\title{
Saúde Mental do Trabalhador no Brasil: Questões emergentes
}

\author{
José Marcondes Macêdo Landim "i ; Martha Maria Macedo Bezerra2; Maria Nizete Tavares Alves3; Miguel Marx ${ }^{4}$
}

Resumo: O objetivo deste estudo é discutir as políticas de saúde mental e do trabalhador, numa perspectiva histórico-contemporânea, bem como refletir sua articulação com a realidade efetiva da saúde do trabalhador e seus ganhos sociais e coletivos. A ideia principal é apontar articulações e desarticulações, partindo-se de breve descrição analítica do que foi considerado positivo nas Conferências Nacionais Brasileiras de Saúde do Trabalhador. Apresenta-se os impasses observados em tais articulações e os desafios políticos para legitimar a Saúde do Trabalhador e a Saúde Mental como campos interdisciplinares.

Palavras-chave: Políticas públicas, Saúde laboral, Saúde Mental.

\section{Mental Health of the Worker in Brazil: Emerging Issues}

\begin{abstract}
The aim of this study is to discuss mental health and worker policies in a historical-contemporary perspective, as well as to reflect their articulation with the effective reality of workers' health and their social and collective gains. The main idea is to point out articulations and disarticulations, starting from a brief analytical description of what was considered positive in the Brazilian National Conferences of Worker's Health. It presents the impasses observed in such articulations and the political challenges to legitimize Worker's Health and Mental Health as interdisciplinary fields.
\end{abstract}

Keywords: Public policies, Occupational health, Mental health.

\section{Introdução}

Em termos de saúde mental, os anos mais difíceis foram quando haviam os famigerados manicômios, verdadeiros depósitos de gente portadora de alguma doença mental ou assemelhado.

\footnotetext{
${ }^{1}$ Mestre em Planejamento e Políticas Públicas pela UECE. Licenciado em Ciências Biológicas pela Universidade Regional do Cariri, Especialista em Botania, pela URCA, Gestão Escolar pela UDESC e Educação de Jovens e Adultos pela FJN. Ex-Secretario Municipal de Educação da Prefeitura Municipal de Barbalha (2006 a 2008). Atualmente é Professor Assistente e Diretor Geral da Faculdade de Juazeiro do Norte, Presidente do Conselho Municipal de Educação de Juazeiro do Norte e Professor rede pública Estadual do Ceará.

${ }^{2}$ Mestrado em Educação pela Universidade Estadual do Ceará. Pedagoga pela Universidade Regional do Cariri, Especialização em Língua Portuguesa pela Universidade Estadual do Ceará, Especialização em Políticas Públicas pela Universidade Regional do Cariri, Especialização em Saude Mental e Psiquiatria pela Universidade Estadual do Vale do Acaraú. Atualmente, cursa o Doutorado em Saúde Coletiva pela Faculdade de Medicina do ABC. Professora concursada da Secretaria de Educação do Estado do Ceará e Professora da Rede Municipal de Juazeiro do Norte, CE. E-mail: marthamacedo2016@gmail.com

${ }^{3}$ Professora Assistente da Universidade Regional do Cariri - URCA. Curso de Enfermagem. Enfermeira da Secretária de Saúde de Juazeiro do Norte. Doutoranda em Ciências da Saúde na Faculdade de Medicina do ABC.

${ }^{4}$ Médico Perito Federal, Servidor da Universidade Federal do Cariri, Médico do Trabalho do Hospital Regional do Cariri, mestrado em terapia intensiva.
} 
Id on Line Revista Multidisciplinar e de Psicologia

Id on Line Multidisciplinary and Psycology Journal

Relativamente as práticas, essas, não respeitavam os direitos humanos, sendo regidas por um modelo psiquiátrico autoritário, que confinava as manifestações de subjetividade que fossem consideradas desviantes ou mesmo contestatórias.

Não havia muita diferenciação entre saúde mental e saúde mental do trabalhador, como campos distintos. Foi à partir da VIII Conferência Nacional de Saúde em 1986, que o movimento da reforma sanitária impôs a ideia de evitar-se a internação de doentes mentais como uma prática corriqueira. Havia toda uma institucionalidade e burocracia associada, que protegia a hospitalização.

Denúncias de maus tratos e crueldade com os pacientes, foram surgindo, culminando numa aliança entre profissionais de saúde, sindicatos, representantes de igrejas, as, familiares de portadores de sofrimento emocional e psíquico, pesquisadores, entre outros, que, alicerçaram a Reforma Sanitária e institucionalização de um Sistema Único de Saúde (DIAS, 1994; SELLIGMANN-SILVA, 1994; VILAÇA MENDES, 1993).

Hoje, 30 anos depois da VIII Conferência Nacional de Saúde e de outras tantas Conferências Nacionais de Saúde Mental e de Saúde do Trabalhador, ainda persistem muitos desafios e novos se apresentam. A terminologia movimento, que antecedeu a expressão reforma sanitária, ainda parece importante para se pensar mais sobre os processos que estão em curso. O SUS e seus derivados programas específicos, parecem em permanente transformação. Uma estabilidade ainda é algo distante ante os avanços políticos e científicos. Há muito conservadorismo que resistem aos jogos de poder no campo específico da saúde mental e em termos de saúde do trabalhador. Quer invocando o retorno de velhas práticas, quer pela desmobilização política e, em busca de um novo desequilíbrio das forças Capital X Trabalho. Outros ainda insistem nos manicômios como solução e em formas mais autoritárias nas relações de trabalho, que aumentam a desigualdade e os direitos sociais até o presente já conquistados (BHABHA, 1998).

Ainda é difícil compreender onde se dá a confluência entre a saúde mental e a saúde do trabalhador. O jogo de forças entre Capital e Trabalho, e as formas de intervenção do Estado esbarram em políticas sociais e políticas econômicas que regem uma governabilidade neoliberal (LEMKE, 2001). Neste sentido, é importante observar que toda política implica numa transformação ou reprodução de uma ordem social, portanto a ausência de programas ou de 
Id on Line Revista Multidisciplinar e de Psicologia

Id on Line Multidisciplinary and Psycology Journal

políticas públicas específicas, precisam ser compreendidas como uma posição do Estado (PECHENY e DEHESA, 2009).

Ambos os programas se conformaram de forma diferenciada à estrutura hierarquizada do SUS, uma vez que optaram por centros de referência especializados como ordenadores da rede de Saúde Mental e de saúde do trabalhador, quais sejam,

Os CAPS - Centros de Atenção Psicossocial, bem como os CRST - Centros de Referência em Saúde do Trabalhador, são hoje centros de referência especializados como organizadores da saúde mental e da saúde do trabalhador. É preciso uma inserção mais efetiva na atenção básica, pois a Saúde do Trabalhador parece que ainda se mantém distanciada da entrada no SUS, reproduzindo características da época do sistema de assistência para os trabalhadores, nos extintos INPS/INAMPS.

Se as políticas definem os direitos, bem como as forma de torná-los efetivos, devem igualmente definir os conteúdos da cidadania e suas questões e ações do Estado. Assim, quando pensarmos em promoção da Saúde Mental para os trabalhadores, devemos nos indagar se essa é uma questão política importante para o Estado e, qual é a compreensão de Saúde Mental que vai nortear as práticas do governo.

\section{Saúde Mental e saúde do trabalhador}

Há inúmeras subjetividades que são indissociáveis em saúde do trabalhador e em Saúde Mental, seja do ponto de vista teórico, da pesquisa ou da intervenção. Pensar saúde, subjetividade e trabalho demanda um agrupamento de idéias e teorias interdisciplinares. Segundo Foucault (1994), é necessário um desdisciplinamento dos objetos e dos problemas, das práticas e dos discursos construídos com base num modelo disciplinar. Em outras palavras, não se trata de aproximar os campos de saberes, mas de se evidenciar as lógicas e formas de produção dos discursos, para que possa ser possível compreender como estes se conformaram aos objetos que estudam e de que forma, sobre eles intervêm.

O movimento sanitário e as políticas de saúde do trabalhador, no Brasil teve inspiração no movimento operário italiano. Conforma enunciados e princípios que permitem o envolvimento mais direto dos trabalhadores nas ações em Saúde do Trabalhador. Isso 
Id on Line Revista Multidisciplinar e de Psicologia

Id on Line Multidisciplinary and Psycology Journal

possibilita uma inversão nas relações de poder e, numa ação que envolve vários campos da ciência, desde as ciências da saúde, exatas e humanas. Na saúde, pela medicina, Enfermagem e pela Psicologia, mais tardiamente contando com a fisioterapia, fonoaudiologia, terapia ocupacional e Educação Física.

As ciências exatas, onde entram as Engenharias e ergonomia. Nas ciências humanas integram as abordagens da Sociologia, Antropologia, Administração de Recursos Humanos e Serviço social contemplando, ainda, uma abordagem jurídica.

Todos, campos conflituosos que possuem ambiguidades internas e que apresentam maior ou menor proximidade com os interesses do Capital, ou com as necessidades dos trabalhadores. Uma confluência de tais campos possibilitaria certamente, uma quebra da hegemonia de determinados saberes sobre os outros e um mais profícuo debate sobre as formas de se compreender a saúde do homem e o seu trabalho. Entretanto, as relações entre saúde, doença e o trabalho, não decorrem somente das diferenças entre os saberes, mas, das disputas políticas entre as partes.

A visibilidade ou a invisibilidade das maneiras de adoecimento no trabalho, bem como os critérios impostos pelas leis e pela ciência, quando do estabelecimento das relações de causa e efeito entre o trabalho e o adoecer, bem como uma maior ou menor valorização de algumas formas em detrimento de outras, é que configuram a lógica que lhes dá sentido (RAMMINGER e NARDI, 2007).

O processo saúde-doença não deve ser analisado fora de um contexto onde acontece. Portanto, não pode ser considerado excluindo-se o sujeito que sofre. $\mathrm{O}$ trabalho é um suporte central para manutenção da vida e, para a significação do eu no coletivo. Daí, a maneira como os indivíduos vivem ou trabalham, está intimamente relacionada ao valor moral que é atribuído ao trabalho. $\mathrm{O}$ adoecimento à partir do trabalho, assim como a capacidade de superação dos limites da doença, são dependentes de uma relação edificada socialmente entre o sujeito e o trabalho, de uma maneira muito particular e individualizada.

Ao analisar-se a implantação de programas de Saúde do Trabalhador no país, fica claro que não se conseguiu romper, com uma hegemonia na compreensão da saúde centrada na fisiologia corporal, e nas formas impostas pelas leis que regulam o adoecimento (baseadas em relação causa-efeito direta, que inclui um agente causador), desconsiderando o sofrimento como algo complexo e subjetivo. 
Id on Line Revista Multidisciplinar e de Psicologia

Id on Line Multidisciplinary and Psycology Journal

\section{Saúde Mental: uma análise das conferências nacionais}

A análise dos documentos, aqui descritos, foi baseada na perspectiva genealógica de Foucault (1999). Sendo assim, busca-se analisar como se organizam as possibilidades de emergência dos saberes em determinadas formas de dominação e resistência, que dão legitimidade ao considerado verdade, para cada período.

\section{A I Conferência Nacional de Saúde do Trabalhador. O discurso da Medicina do Trabalho versus a saúde do trabalhador}

A I Conferência Nacional de Saúde do Trabalhador, foi raizada em dezembro de 1986,e teve seus conteúdos utilizados na Política Nacional de Saúde do Trabalhador, que posteriormente foram incorporados a Constituição Federal de 1988 e na Lei nº 8080, de 1990. $\mathrm{O}$ empresariado foram os principais atores ausentes nas discussões e deliberações, com $1 \%$ apenas, dos delegados participantes.

O relatório final (BRASIL, 1986), estabeleceu um consenso onde a saúde dos trabalhadores extrapolaria os limites da saúde laboral, introduzindo o conceito ampliado de saúde, demonstrando e afirmando uma necessidade de se revisar as leis, com vistas a uma ampliação das listas de doenças ocupacionais, de forma a assegurar os mesmos direitos a todos, seja em que área trabalhe. A conferência enfatizou, em diversos momentos, a necessidade da criação de um Sistema Único de Saúde, bem como de programas específicos para atendimento ao trabalhador. Este sistema deveria contar, com uma política de recursos humanos, capaz de reorientar a formação de trabalhadores da área de saúde pública, com remuneração digna.

Quanto à fiscalização, o relatório sugere que esta seja uma responsabilidade do SUS, juntamente com a participação dos trabalhadores, para evitar-se que os agentes fiscais tenham vínculos com a empresa a ser fiscalizada. O relatório sugeriu também a necessidade do envolvimento dos sindicatos, nas questões de saúde do trabalhador, como objetivo de luta. Também ressaltou a importância de uma maior organização dos trabalhadores, no sentido de 
Id on Line Revista Multidisciplinar e de Psicologia

Id on Line Multidisciplinary and Psycology Journal

proporcionar a abertura de novos espaços. Em seu último eixo, estabeleceu os direitos básicos de saúde do trabalhador.

\section{A II Conferência Nacional de Saúde do Trabalhador e a construção de uma política de saúde voltada para o trabalhador}

A II Conferência Nacional de Saúde do Trabalhador aconteceu oito anos depois, e já sob uma Constituição Federal e Lei Orgânica da Saúde, onde se seguia incorporada a atenção à saúde dos trabalhadores, como sendo de responsabilidade do SUS. Teve como tema central: construindo uma política de saúde do trabalhador, e como temas acessórios: desenvolvimento, cenário de Saúde do Trabalhador de 1986 a 1993, meio ambiente e saúde e, perspectivas e estratégias de avanço na construção da política nacional de saúde do trabalhador.

Um dos principais ganhos dessa conferência, foram: a definição da unificação de ações visando a Saúde do Trabalhador no SUS e, uma ampla discussão sobre as dimensões políticas, sociais, econômicas e técnicas, dessa política pública (BRASIL, 1994).

O painel sobre Saúde Mental foi coordenado pelo DIESAT - Departamento Intersindical de Estudos e Pesquisas de Saúde e dos Ambientes de Trabalho, que avaliou o reconhecimento internacional de que, algumas formas de trabalho, envolvendo produtos químicos e novas tecnologias, são consideradas nocivas à Saúde Mental. mas, apenas à partir da década de 80, os pesquisadores brasileiros puderam ampliar as ações em saúde mental do trabalhador, tanto dos serviços públicos como dos sindicatos. Por essa época, foram realizados os primeiros estudos pelo DIESAT, por demandas sindicais, com bancários (1985) e metroviários (1986), para conhecer os efeitos à Saúde Mental pelas condições de trabalho, especialmente quanto ao trabalho automatizado.

Em outra exposição, também pelo DIESAT, foi demonstrado que a Saúde Mental do trabalhador não se trata de uma preocupação generalizada do movimento sindical. Que, as queixas e os problemas de sofrimento mental dos trabalhadores, chegam aos sindicatos travestidos na forma de manifestações orgânicas ou de problemas funcionais com a organização do trabalho, ou com a chefia de maneira geral, ou ainda, como dificuldades nas relações interpessoais fora, ou no trabalho. 
Id on Line Revista Multidisciplinar e de Psicologia

Id on Line Multidisciplinary and Psycology Journal

Em duas pesquisas citadas, ficou evidenciado que, tanto os bancários como metroviários, apresentaram uma grande coincidência em termos de perfil de sofrimento mental. Concluiu-se que uma questão emergente seria o controle do processo produtivo, e da tecnologia aplicada a ele. Minimizou-se assim, a prática recorrente de se localizar o problema mental em características individuais de cada pessoa, ao negar sua relação com as condições de vida e de trabalho.

O relatório ainda apresentou itens mais específicos sobre a Saúde Mental, como uma necessidade do reconhecimento de doenças profissionais (p. 33) e uma sugestão sobre que as empresas privadas e públicas deveriam manter programas educativos quanto ao alcoolismo (p. $45)$.

\section{A III Conferência Nacional de Saúde do Trabalhador. Não ao adoecimento.}

A III CNST realizou-se mais de 10 anos após a segunda CNST, sendo esta realizada com a participação conjunta dos Ministérios da Saúde, do Trabalho e Emprego, e da Previdência Social. A ideia foi integrar as ações que são direcionadas à Saúde do Trabalhador brasileiro.

Dentre as propostas, estava a discussão de uma política intersetorial, como a integração e a implantação da RENAST - Rede Nacional de Atenção Integral à Saúde do Trabalhador, que foi instituída em 2002.

Sob a desígnia trabalhar, sim, adoecer, não, esta conferência propôs três eixos temáticos, em forma de perguntas: a)Como garantir a integralidade e a transversalidade da ação do Estado em saúde dos(as) trabalhadores(as)?; B)Como incorporar a saúde dos(as) trabalhadores(as) nas políticas de desenvolvimento sustentável no País?; c) Como efetivar e ampliar o controle social em saúde dos(as) trabalhadores(as)?. Dessa forma, outros diversos textos apresentados, apoiavam a temática sugerida (BRASIL, 2005).

Neste evento, foram aprovadas 362 resoluções, mas apenas 10 delas $\left(n^{\circ} \mathrm{s} 31,54,78,86\right.$, 139, 144, 151, 155, 156 e 253) foram mais enfáticas quanto ao tema Saúde Mental e trabalho. Medidas relacionadas ao assédio moral no trabalho (nº 54, 78, 151,155), Garantia à atenção integral à saúde, incluindo Saúde Mental ( ${ }^{\circ}$ s 31 e 156), e outras que cuidam de Crimes contra 
Id on Line Revista Multidisciplinar e de Psicologia

Id on Line Multidisciplinary and Psycology Journal

a higidez física e mental do trabalhador; Que envolvem a inserção de portadores de transtornos mentais no mundo do trabalho ( $\left.n^{\circ} 139\right)$; Que enfatizam a importância de métodos e técnicas de prevenção aos desconfortos físicos e mentais no trabalho $\left(n^{\circ} 144\right)$ e, As que destacam os temas que devem ser priorizados nos estudos e pesquisas, entre eles as doenças (inclusive mentais) relacionadas ao uso de agrotóxicos (nº 253) (Brasil, 2006).

Lacaz, 2007, nos orienta que, as resoluções da III CNST ora parecem ratificar as resoluções da II CNST, ora parecem expressar um retorno às formulações da saúde ocupacional. Para este autor, o conservadorismo das resoluções parece fruto da "fragilidade atual do movimento sindical, aliada à postura pouco engajada da Academia e ao desenvolvimento de políticas públicas reducionistas” (p. 764).

Um evento que precisa de destaque, foi o Seminário Nacional de Saúde Mental e Trabalho, que foi realizado em 25 de fevereiro de 2008, na Fundacentro, em São Paulo. Dele participaram profissionais de diversas entidades, a saber: da Fundacentro, de universidades, dos Centros de Referência em Saúde do Trabalhador, do Serviço de Saúde Ocupacional do Hospital das Clínicas da USP, do Conselho Regional de Psicologia de São Paulo e do Senac de São Paulo, dentre outras instituições.

Nessa reunião, foi proposta a necessidade de uma rede permanente de integração para discutir e efetivar ações relacionadas à Saúde Mental e ao trabalho. A ideia foi de se desenvolver pesquisas integradas para subsidiar propostas de políticas públicas de atenção à Saúde Mental do trabalhador, mais abrangentes, desde a promoção à saúde, prevenção de agravos, assistência e reabilitação profissional. Foi consensual, a decisão pela criação do Fórum Interinstitucional permanente sobre Saúde Mental e Trabalho, com uma série de atividades propostas para o ano de 2008, à época. Dentre as quais:

a) A proposta de um protocolo sobre Saúde Mental e trabalho para notificação compulsória de 11 agravos relacionados ao trabalho, dentre esses, os transtornos psíquicos;

b) A apreciação e emissão de pareceres, com o intuito de acompanhar e contribuir na definição de Diretrizes de Conduta Médico-pericial em Transtorno Mental;

c) A criação de uma rede de Saúde Mental e trabalho, bem como de um fórum virtual;

d) Buscar reunir pesquisadores, profissionais e movimento sindical, para discussões acerca da Saúde Mental e trabalho. 


\begin{tabular}{|c|c|c|c|}
\hline Conferência/ano & $\begin{array}{l}\text { Contexto/ } \\
\text { participantes }\end{array}$ & Eixos principais & Saúde Mental \\
\hline $\begin{array}{l}\text { I Conferência } \\
\text { Nacional de } \\
\text { Saúde do Trabal- } \\
\text { hador } \\
\text { (1986) }\end{array}$ & $\begin{array}{l}\text { Conferência Nacional } \\
\text { de Saúde (março de } \\
1986 \text { ) } \\
399 \text { delegados, } \\
\text { sendo } \\
46 \% \text { representantes } \\
\text { de trabalhadores, } \\
40 \% \text { do } \\
\text { Estado, } 9 \% \text { das } \\
\text { universidades e } 5 \% \\
\text { de } \\
\text { outras categorias }\end{array}$ & $\begin{array}{l}\text { 1. Diagnóstico da } \\
\text { situação de saúde e } \\
\text { segurança dos } \\
\text { trabalhadores } \\
\text { 2. Novas alternativas } \\
\text { de atenção à saúde } \\
\text { dos trabalhadores } \\
\text { 3. Política Nacional de } \\
\text { Saúde e Segurança dos } \\
\text { Trabalhadores }\end{array}$ & $\begin{array}{l}\text { Em sua última } \\
\text { temática, aparece uma } \\
\text { clara preocupação } \\
\text { com o portador de } \\
\text { deficiência, que deve } \\
\text { ter acesso ao trabalho, } \\
\text { acompanhamento } \\
\text { médico, psicológico e } \\
\text { social, e aposentadoria } \\
\text { especial com } 25 \text { anos de } \\
\text { trabalho. } \\
\text { Sugere, ainda, a } \\
\text { substituição do atestado } \\
\text { de sanidade física e } \\
\text { mental por atestado de } \\
\text { aptidão para a função. }\end{array}$ \\
\hline $\begin{array}{l}\text { Il Conferência } \\
\text { Nacional } \\
\text { de Saúde do } \\
\text { Trabalhador } \\
\text { (1994) }\end{array}$ & $\begin{array}{l}\text { Constituição } \\
\text { Federal de } \\
1988 \text { e Lei } \\
\text { Orgânica da } \\
\text { Saúde, de } 1990 . \\
\text { IX Conferência } \\
\text { Nacional de Saúde, } \\
\text { de } \\
1992 \\
560 \text { delegados, dos } \\
\text { quais } 65,7 \% \\
\text { representantes dos } \\
\text { trabalhadores, } \\
31,1 \% \text {, } \\
\text { do Estado, e } 3,2 \% \\
\text { dos } \\
\text { empregadores }\end{array}$ & $\begin{array}{l}\text { Tema: } \\
\text { Construindo uma } \\
\text { política de saúde } \\
\text { do trabalhador. } \\
\text { Temas } \\
\text { complementares: } \\
\text { 1. desenvolvimento, } \\
\text { meio ambiente e } \\
\text { saúde } \\
2 \text { cenário da Saúde } \\
\text { do Trabalhador } \\
\text { de } 1986 \text { a } 1993 \text { e } \\
\text { perspectivas } \\
\text { 3. estratégias } \\
\text { de avanço na } \\
\text { construção da } \\
\text { Política Nacional } \\
\text { de Saúde do } \\
\text { Trabalhador }\end{array}$ & $\begin{array}{l}\text { Um dos painéis específicos } \\
\text { foi sobre Saúde Mental e } \\
\text { trabalho, onde se fez uma } \\
\text { avaliação da relação entre } \\
\text { Saúde Mental e trabalho } \\
\text { no Brasil. No relatório final, } \\
\text { foi apontada a necessidade } \\
\text { de se contem plarem } \\
\text { aspectos de Saúde Mental } \\
\text { no reconhecimento das } \\
\text { doenças profissionais, a } \\
\text { inclusão dos profissionais } \\
\text { de serviço social e de } \\
\text { Psicologia nas equipes de } \\
\text { saúde do trabalhador, } \\
\text { ainda, que, na vigilância } \\
\text { em saúde do trabalhador, } \\
\text { sejam consideradas as } \\
\text { relações profissionais e } \\
\text { institucionais a que estão } \\
\text { submetidos os profissionais } \\
\text { de saúde, inclusive os de } \\
\text { Saúde Mental. }\end{array}$ \\
\hline $\begin{array}{l}\text { III Conferência } \\
\text { Nacional de } \\
\text { Saúde do Trabal- } \\
\text { hador } \\
\text { (2005) }\end{array}$ & $\begin{array}{l}\text { Criação da RENAST } \\
\text { (2OO2) } \\
\text { Política Nacional de } \\
\text { Segurança e Saúde } \\
\text { do Trabalhador (Por- } \\
\text { taria Interministerial } \\
\text { no800/O5) } \\
\text { XII CNS (2003, que } \\
\text { indicou a necessi- } \\
\text { dade de realização } \\
\text { da conferencia) } \\
\text { Política Nacional } \\
\text { de Saúde do Tra- } \\
\text { balhador (Portaria } \\
\text { no1125/O5)" } \\
\text { Convocação con- } \\
\text { junta de três Minis- } \\
\text { térios: da Saúde, do } \\
\text { Trabalho e Emprego } \\
\text { e da Previdência } \\
\text { Social }\end{array}$ & $\begin{array}{l}\text { Tema: } \\
\text { trabalhar, sim, } \\
\text { adoecer, não! } \\
\text { Eixo I - Como } \\
\text { garantir a integrali- } \\
\text { dade e a transver- } \\
\text { salidade da ação do } \\
\text { Estado } \\
\text { em saúde dos(as) } \\
\text { trabalhadores(as)? } \\
\text { Eixo II - Como } \\
\text { incorporar a } \\
\text { saúde dos(as) } \\
\text { trabalhadores(as) } \\
\text { nas políticas de } \\
\text { desenvolvimento } \\
\text { sustentável? } \\
\text { Eixo III - Como } \\
\text { efetivar e ampliar o } \\
\text { controle social em } \\
\text { saúde dos(as) } \\
\text { trabalhadores(as)? }\end{array}$ & $\begin{array}{l}\text { O relatório apresenta } \\
362 \text { resoluçóes, divididas } \\
\text { entre os três diferentes } \\
\text { eixos. Destas, apenas } \\
10 \text { citam a relação entre } \\
\text { Saúde Mental e trabalho, } \\
\text { destacando-se as medi- } \\
\text { das relacionadas ao as- } \\
\text { sédio moral no trabalho. }\end{array}$ \\
\hline
\end{tabular}

Quadro 1. Saúde Mental nas Conferências Nacionais de Saúde do Trabalhador 
Id on Line Revista Multidisciplinar e de Psicologia

Id on Line Multidisciplinary and Psycology Journal

A não incorporação de tais premissas se chocaria com diversos estudos que apontaram os efeitos maléficos e crescentes do capitalismo contemporâneo, com consequências para a Saúde Mental dos trabalhadores, tais como: um aumento no individualismo, a criação de uma cultura narcisista, uma sociedade de incertezas (Beck, Giddens \& Lash, 1997), maior competição e minimização das garantias de estabilidade, promotoras de possibilidade de desestabilização do caráter dos trabalhadores (Sennett, 2010). Na mesma direção, Bauman (1998) demonstra que o sentimento maior passa a ser a sensação de incerteza sobre o futuro do mundo.

Enriquez (1997), denunciou sobre as consequências nefastas para o psiquismo, as práticas que envolvem novas formas de gestão. Isso é, uma busca a qualquer custo pelo sucesso pessoal individual, responsabilizando totalitariamente o indivíduo como único responsável pelo seu destino (Castel, 2009). Trata-se de uma vitória neoliberal que produz sensações de incapacidade que se expressam altos índices de suicídio, normalmente relacionados ao trabalho em diversos países, como, por exemplo, recentemente na crise da França, analisada por Cristhophe Dejours e Florence Bègue (Castel, 2009).

\section{Considerações finais}

Uma reflexão sobre as Conferências de Saúde do Trabalhador e sobre os debates que implicaram em suas resoluções, observa-se que a questão do sofrimento psíquico parece tratada de forma tímida, pois que, somente tangencia o as questões institucional-legais que regulam a saúde dos trabalhadores no Brasil. A Saúde Mental, embora apresentada nas três Conferências Nacionais de Saúde do Trabalhador, tiveram ênfases distintas. Apareceu de forma muito incipiente na I e na III Conferências. Na II Conferência Nacional de Saúde do Trabalhador, realmente parece ter trado com maior relevância a relação entre Saúde Mental e trabalho, sobretudo quanto a participação maior de profissionais ligados às universidades.

Este estudo, certamente implicará em maior visibilidade a certos elementos políticos e sociais da saúde do trabalhador, demonstrando a importância dos constantes debates e reivindicações quanto a saúde mental do trabalhador. 
Id on Line Revista Multidisciplinar e de Psicologia

Id on Line Multidisciplinary and Psycology Journal

Ainda são imensos, mesmo que sutis, as problemáticas e implicações que cercam esta temática. Até porque, se relacionam com questões éticas, que dizem respeito ao lugar que reservamos para o outro, enquanto sujeitos e cidadão de direito, nas nossas relações cotidianas, seja ela patrão-empregado, governo/servidor, profissional de saúde-usuário, ou mesmo nas relações servidor-servidor, usuário-usuário, etc. Portanto, o que se objetivou foi apontar os caminhos, até aqui percorridos, na luta por modos de trabalhar mais adequados, que permitam um maior prazer, em detrimento do sofrimento.

Certamente, políticas de Saúde do Trabalhador que incluam o princípio da integralidade nas questões relativas à Saúde Mental, devem atentar para as configurações contemporâneas que se apresentam para o trabalho. Estas estão apontando para maiores riscos de acidentes, de contaminação e de doenças do trabalho, tanto as clássicas como as novas formas de assédio, quanto às pressões para produção, ameaças e precarização do trabalho. São todas formas de violência produtoras de condições psicossociais de adoecimento do trabalhador. Assim, pensar e discutir sobre a renovação das políticas públicas nesse campo, tende a conduzir a melhores condições de vida e de trabalho para todo e qualquer cidadão.

\section{Referências}

BAUMAN, Z. O mal-estar da pós-modernidade. Rio de Janeiro: Jorge Zahar Editor, 1998.

BECK, U., GIDDENS, A., e LASH, S. Modernização reflexiva: política, tradição e estética na ordem social moderna. São Paulo: Editora da Unesp, 1997.

BRASIL. Ministério da Saúde. I Conferência Nacional de Saúde do Trabalhador. Relatório Final. Brasília, DF: Ministério da Saúde, 1986.

BRASIL. Ministério da Saúde. II Conferência Nacional de Saúde do Trabalhador. Relatório Final. Brasília, DF: Ministério da Saúde, 1994.

BRASIL. Ministério da Saúde. III Conferência Nacional de Saúde do Trabalhador: Coletânea de textos. Brasília, DF: Ministério da Saúde, 2005.

BRASIL. Ministério da Saúde. III Conferência Nacional de Saúde do Trabalhador. Resoluções. Brasília, DF: Ministério da Saúde, 2006. 
Id on Line Revista Multidisciplinar e de Psicologia

Id on Line Multidisciplinary and Psycology Journal

BHABHA, H. O local da cultura. Belo Horizonte: Ed. UFMG.

CASTEL, R. . La montée des incertitudes: Travail, protections, statut de l'individu. Paris: Seuil, 2009.

DIAS, E. C. . A atenção à saúde dos trabalhadores no setor saúde no Brasil (SUS): realidade, utopia ou fantasia? Tese de doutorado, Universidade Estadual de Campinas, Campinas, SP, 1994.

ENRIQUEZ, E. O indivíduo preso na armadilha da estrutura estratégica. Revista de Administração de Empresas, 1997, 37(1), 18-29.

FOUCAULT, M. La poussière et le nuage. In M. Foucault, Dits et écrits (pp. 10-19). Paris : Gallimard, 1994.

FOUCAULT, M. Verdade e poder. In R. Machado (Org.), Microfísica do poder (pp. 1-14). Rio de Janeiro: Ed. Graal, 1999.

LACAZ, F. A. C. O campo saúde do trabalhador: resgatando conhecimentos e práticas sobre as relações trabalho-saúde. Cadernos de Saúde Pública, 2007, 23(4), 757-766.

LEMKE, T. The birth of bio-politics: Michel Foucault's lecture at the Collège de France on neo-liberal governmentality. Economy \& Society, 2001, 30(2), 190-207.

RAMMINGER, T., NARDI, H. C. Saúde Mental e saúde do trabalhador: análise das conferências nacionais brasileiras. Psicologia: Ciência e Profissão, 2007, 27(4), 680-693.

SELLIGMANN-SILVA, E. Desgaste mental no trabalho dominado. Rio de Janeiro: Ed. da UFRJ/Cortez, 1994.

SENNETT, R. A corrosão do caráter: consequências pessoais do trabalho no novo capitalismo. Rio de Janeiro: Record, 2010.

VILAÇA-MENDES, E. Distrito sanitário. São Paulo: Hucitec, 1993.

Como citar este artigo (Formato ABNT):

LANDIM, J.M.M.; BEZERRA, M.M.M.; ALVES, M.N.T,; MARX, M. Saúde mental do trabalhador no Brasil: questões emergentes. Id on Line Revista Multidisciplinar e de Psicologia, Janeiro de 2017, vol.10, n.33, Supl 2. p. 112-125. ISSN: 1981-1179.

Recebido: 03/01/2017

Aceito: 10/01/2017 